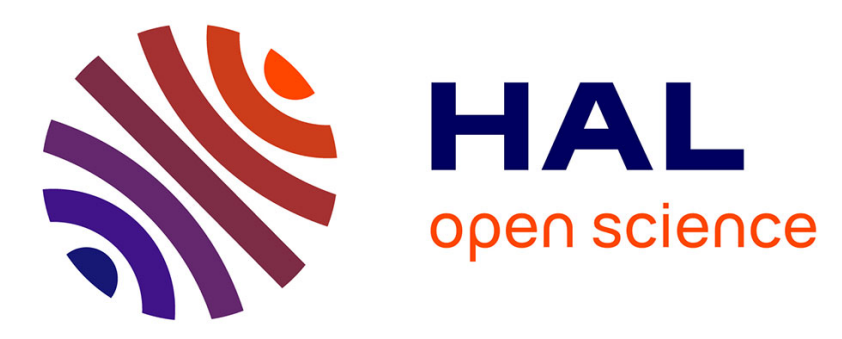

\title{
A Dendritic Nanostructured Copper Oxide Electrocatalyst for the Oxygen Evolution Reaction
}

Huan Tran Ngoc, Marc Rousse, Sandrine Zanna, Ivan T. Lucas, Xiangzhen

$\mathrm{Xu}$, Nicolas Menguy, Marc Mougel, Marc Fontecave

\section{- To cite this version:}

Huan Tran Ngoc, Marc Rousse, Sandrine Zanna, Ivan T. Lucas, Xiangzhen Xu, et al.. A Dendritic Nanostructured Copper Oxide Electrocatalyst for the Oxygen Evolution Reaction. Angewandte Chemie, 2017, 129 (17), pp.4870-4874. 10.1002/ange.201700388 . hal-01514946

\section{HAL Id: hal-01514946 https://hal.sorbonne-universite.fr/hal-01514946}

Submitted on 26 Apr 2017

HAL is a multi-disciplinary open access archive for the deposit and dissemination of scientific research documents, whether they are published or not. The documents may come from teaching and research institutions in France or abroad, or from public or private research centers.
L'archive ouverte pluridisciplinaire HAL, est destinée au dépôt et à la diffusion de documents scientifiques de niveau recherche, publiés ou non, émanant des établissements d'enseignement et de recherche français ou étrangers, des laboratoires publics ou privés. 


\title{
Dendritic Nanostructured Copper Oxide Electrocatalyst For Oxygen Evolution Reaction
}

\author{
Tran Ngoc Huan ${ }^{[a]}$, Gwenaëlle Rousse, ${ }^{[b]}$ Sandrine Zanna, ${ }^{[c]}$ Ivan T. Lucas, ${ }^{[d]}$ Xiangzhen Xu, ${ }^{[e]}$, Nicolas \\ Menguy, ${ }^{[\mathrm{f}]}$ Victor Mouge ${ }^{[\mathrm{a}] *}$, Marc Fontecave ${ }^{[\mathrm{a}] *}$
}

\begin{abstract}
In order to use water as the source of electrons for proton or $\mathrm{CO}_{2}$ reduction within electrocatalytic devices, catalysts are required for facilitating the proton-coupled multi-electron Oxygen Evolution Reaction (OER, $2 \mathrm{H}_{2} \mathrm{O} \rightarrow \mathrm{O}_{2}+4 \mathrm{H}^{+}+4 \mathrm{e}^{-}$). These catalysts, ideally based on cheap and earth abundant metals, have to display high activity at low overpotential, good stability and selectivity. While numerous examples of $\mathrm{Co}, \mathrm{Mn}, \mathrm{Ni}$ catalysts were recently reported for water oxidation, only few examples were reported using copper, despite promising efficiencies. We report here a rationally designed nanostructured copper/copper oxide electrocatalyst for OER. This material derives from conductive copper foam passivated by a copper oxide layer and further nanostructured by electrodeposition of $\mathrm{CuO}$ nanoparticles. The generated electrodes are highly efficient for catalyzing selective water oxidation to dioxygen with an overpotential of $290 \mathrm{mV}$ at $10 \mathrm{~mA} / \mathrm{cm}^{-2}$ in $1 \mathrm{M} \mathrm{NaOH}$ solution.
\end{abstract}

Water splitting into oxygen and hydrogen is one of the most appealing strategies for storing renewable energies in the form of chemical energy. ${ }^{[1-3]}$ However the water oxidation half reaction, also called oxygen evolution reaction (OER), providing the

[a] Dr. T. N. Huan, Dr. V. Mougel, Prof. M. Fontecave Laboratoire de Chimie des Processus Biologiques, CNRS UMR 8229

Collège de France, UPMC Univ Paris 06

11 Place Marcelin Berthelot, 75231 Paris Cedex 05, France

E-mail: victor.mougel@college-de-france.fr, marc.fontecave@college-de-france.fr

[b] Dr. G. Rousse

Laboratoire de Chimie du Solide et Energie, UMR 8260

Collège de France, 11 Place Marcelin Berthelot, 75231 Paris Cedex 05, France.

Sorbonne Universités, UPMC Univ Paris 06

4 place Jussieu, 75005 Paris, France.

[c] Dr. S. Zanna

Chimie ParisTech, PSL Research University, CNRS, Institut de

Recherche de Chimie Paris (IRCP)

11 rue Pierre et Marie Curie, 75005 Paris, France.

[d] Dr. I.T. Lucas

Laboratoire Interfaces et Systèmes Electrochimiques, UMR 8235

Sorbonne Universités, UPMC Univ Paris 06

4 place Jussieu, 75005 Paris, France.

[e] Dr. X. Xu

Laboratoire de Physique et d'Etude des Matériaux

CNRS, ESPCI Paris, PSL Research University, UPMC Univ Paris

06, Sorbonne-Universitiés

10 Rue Vauquelin, 75005 Paris, France

[f] Pr. N. Menguy

Institut de Minéralogie et de Physique des Milieux Condensés, UMR 7590 CNRS, Sorbonne Universités, UPMC Univ Paris 06 4 place Jussieu, 75005 Paris, France.

Supporting information for this article is given via a link at the end of the document. electrons required for proton reduction, implies the loss of 4 electrons and four protons from two water molecules with concomitant formation of an O-O bond. This complex process is thus fraught with slow kinetics and requires efficient and stable catalysts. Metal oxides, preferably based on non-noble transition metals (Co, $\mathrm{Ni}, \mathrm{Mn}, .$. ), are the most popular candidates and thus have been extensively investigated with renewed interest during the last decade. ${ }^{[4-10]}$ In that context, few recent examples have indicated that CuO-based materials electrodeposited from molecular $\mathrm{Cu}$ complexes or simple $\mathrm{Cu}$ salts could display interesting performances for water oxidation. ${ }^{[11-17]}$ While these are still outperformed by state of the art catalysts ${ }^{[6-10]}$ (Tables S1 and S2), the low cost and large abundance of copper justifies pursuing studies on rationally designed copper oxide electrodes. With the aim of lowering the overpotential observed for water oxidation with such systems, we targeted the preparation of a copper-based material constituted of a highly conductive support - to limit resistivity of the electrode - possessing a high surface area and a large number of active sites - to facilitate charge transfer and increase overall reaction rates. Meeting these last two requirements typically involves the use of nanoparticles, but the large number of grain boundaries in such systems significantly increases the overall resistivity and overpotential, and their dense packing when immobilized at an electrode reduces the efficiency of mass transfer. Both of these concerns could be addressed by the immobilisation of a thin layer of active nanoparticles on a high surface area conductive support.

In this paper, we report the three-step preparation of a coppersupported high surface area porous dendritic $\mathrm{Cu} / \mathrm{Cu}_{2} \mathrm{O} / \mathrm{CuO}$ material further nanostructured with a thin layer of electrodeposited $\mathrm{CuO}$ nanoparticles (Scheme 1). This noble metal free system presents unprecedented water oxidation electrocatalytic activity and stability at low overpotential in a wide range of conditions. ${ }^{[18]}$

Scheme 1. Strategy for nanostructured copper oxide electrodes. (a) Macropores resulting from the $\mathrm{H}_{2}$ bubbles template. (b) Typical dendritic structure of the material. (c) Sectional view of a dendrite.
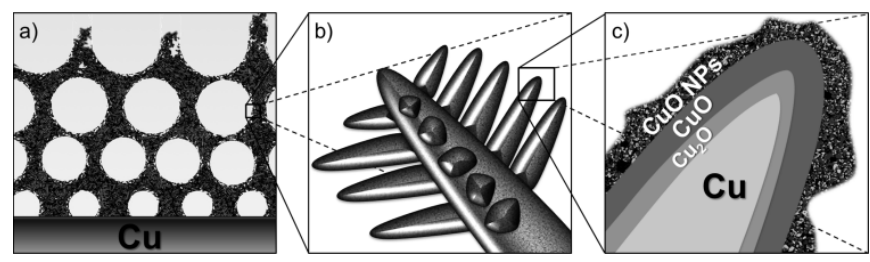

As a conductive support, we used a robust high surface area three-dimensional porous dendritic Cu material, $\mathbf{1}$, generated via a hydrogen evolution assisted electrodeposition approach. ${ }^{[19-21]}$ For that purpose we followed a previously reported procedure involving the electrodeposition of $\mathrm{CuSO}_{4}$ on a $\mathrm{Cu}$ plate in acidic 
conditions using a large current density $\left(0.5 \mathrm{~A} . \mathrm{cm}^{-2}\right.$, see ESI for details). ${ }^{[21]}$ The porous structure of this material, resulting from the combination of copper dendritic growth and the concomitant generation of a foam due to intense hydrogen bubbling, (scheme $1 \mathrm{a}-\mathrm{b}$ ) is particularly suited for electrocatalytic applications, as the macropores allow for a fast diffusion of species to the micropores, hence avoiding mass transfer limitations. ${ }^{[19-21]}$

Metallic copper is typically not stable under the conditions required for water oxidation, ${ }^{[22]}$ but recent work have proven that surface $\mathrm{CuO}$ films on $\mathrm{Cu}$ electrodes are very effective at preventing anodic corrosion under catalytic water oxidation conditions. ${ }^{[15]}$ In order to generate such a passivation film on the dendritic material, 1 was annealed in air at $300^{\circ} \mathrm{C}$ during $30 \mathrm{~min}$ affording material 2. Powder X-Ray Diffraction (XRD) patterns of the electrode material after annealing showed the presence of crystalline $\mathrm{Cu}, \mathrm{Cu}_{2} \mathrm{O}$ and small amounts of $\mathrm{CuO}$, while only $\mathrm{Cu}$ and trace amounts of $\mathrm{Cu}_{2} \mathrm{O}^{[23]}$ could be observed before the high temperature treatment (Figure $1 \mathrm{~d}$ ). X-ray Photoelectron Spectroscopy (XPS) of 2 presents Cu $2 p_{3 / 2}$ and $2 p_{1 / 2}$ peaks at 933.6 and $953.8 \mathrm{eV}$ and a Cu-Auger peak at $918.0 \mathrm{eV}$ (Figure $\mathrm{S} 1$ ), indicating that $\mathrm{CuO}$ is the main surface species (within a 6 $\mathrm{nm}$ layer), ${ }^{[24]}$ in agreement with the analysis of the $O 1 \mathrm{~s}$ region of the XPS spectra, revealing the presence of a main $\mathrm{O}^{2-}$ signal at $529.6 \mathrm{eV}$. Raman spectroscopy of the material (Figure S2) revealed the presence of $\mathrm{Cu}_{2} \mathrm{O}$ and $\mathrm{CuO}$ signals. ${ }^{[25]}$ Scanning Transmission Electron Microscopy - X-ray Energy-Dispersive spectroscopy (STEM-XEDS) analyses (Figure S3) confirmed the increase in the oxygen content after thermal treatment, while Scanning electron microscopy (SEM) and Transmission Electron Microscopy (TEM) analyses, Figures 1 a-c and S4, showed that the initial porous and dendritic structure of the solid foam was retained after annealing while being covered by a thin amorphous layer. This, combined with the observation of a significant amount of metallic copper after annealing, demonstrates that the material is likely only oxidized in surface, keeping a metallic copper core and hence a good conductivity. a)
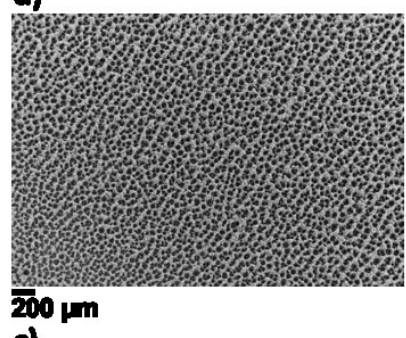

c)

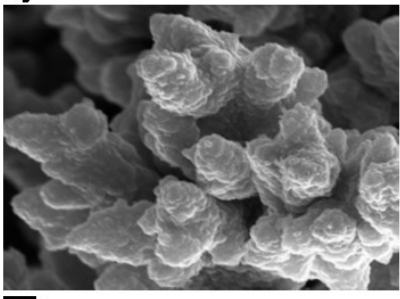

$200 \mathrm{~nm}$ b)

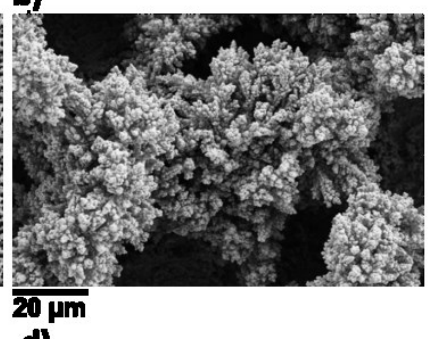

d)

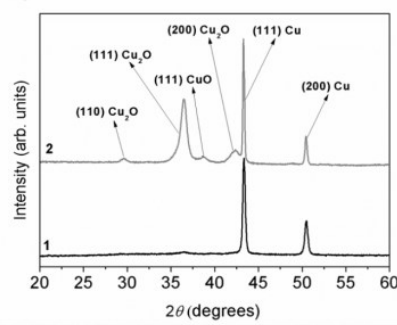

Figure 1. (a)-(c) SEM images of electrode 2. (d) Powder XRD patterns $(\lambda \mathrm{cu}=$ $1.54 \AA$ ) of materials 1 \& 2.

Finally, nanostructuration of the surface of material $\mathbf{2}$ was achieved following a methodology recently reported by our group and others ${ }^{[12,26-29]}$ and based on the electrodeposition of nanoparticles (NPs) using $\mathrm{Cu}$ complexes bearing $\mathrm{N}$-containing ligands as precursors. Here NP electrodeposition was achieved applying 2 Cyclic Voltammetry (CV) cycles (between -0.5 and 1 $\mathrm{V}$ vs $\mathrm{Ag} / \mathrm{AgCl})$ to a $\mathrm{Cu}(\text { imidazole })_{4} \mathrm{Cl}_{2}(0.2 \mathrm{mM})$ solution in acetonitrile (3\% water $\mathrm{v} / \mathrm{v})$ (See ESI for details). ${ }^{[30]}$

SEM characterization of the resulting material, named $\mathbf{3}$, clearly showed that this treatment did not alter the macroporosity and the dendritic structure of the material but resulted in a significant modification of the surface (Figure 2 a). Further analysis by TEM revealed the formation of a thin layer of small nanoparticles (< $10 \mathrm{~nm}$ ) on top of the dendrites (Figure $2 \mathrm{~b}-\mathrm{c}$ ). XPS of 3 is very similar to 2, exhibiting two peaks at 933.7 and $953.8 \mathrm{eV}$ and a Cu-Auger peak at $917.7 \mathrm{eV}$, characteristic of CuO (Figure S5). Powder XRD analysis of $\mathbf{3}$ revealed a largely increased ratio of $\mathrm{CuO}$ with respect to 2 (Figure $2 \mathrm{~d}$ ), and fitting of the broad $\mathrm{CuO}$ peaks using Scherrer's equation indicated an average particle size of $6 \mathrm{~nm}$, in line with the dimensions of the nanoparticles observed by TEM. Raman spectra before and after deposition of the nanoparticles proved very similar, the only noticeable difference being an increase of the $\mathrm{CuO}$ signal at $645 \mathrm{~cm}^{-1}$ with respect to the $\mathrm{Cu}_{2} \mathrm{O}$ signals at 220,425 and $510 \mathrm{~cm}^{-1}[25,31$ (Figure S2), in agreement with the XPS and XRD analysis. These data suggest that the deposited nanoparticles are mainly composed of CuO. In addition, XPS and XEDS measurements confirmed the absence of nitrogen and chlorine in this layer (Figures S5-S6), thus ruling out the presence of imidazole and Chlorine ligands within this $\mathrm{CuO}$ film. ${ }^{[32]}$ a)

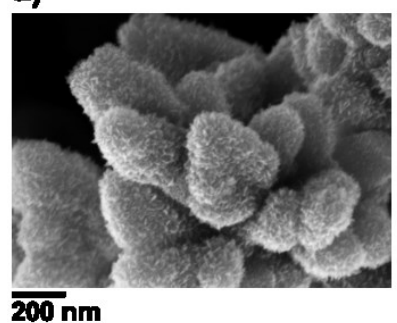

$200 \mathrm{~nm}$

c)

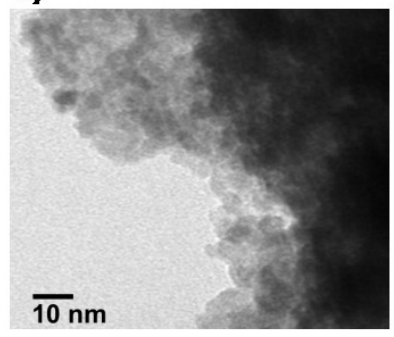

b)

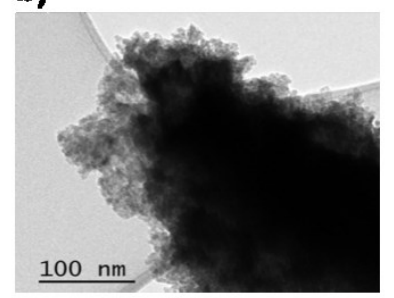

d)

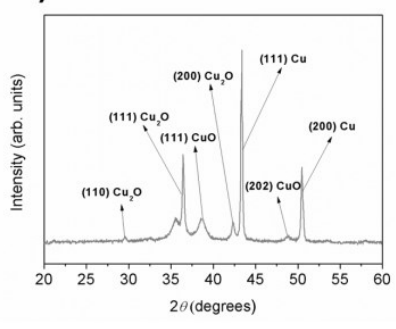

Figure 2. (a) SEM and (b)-(c) TEM images of electrode 3. Powder XRD pattern $\left(\lambda_{\mathrm{Cu}}=1.54 \AA\right)$ of electrode 3

In order to gain deeper insight onto the multilayer structure and chemical composition of this material, Focused lon Beam (FIB) cross sections (Figure S6) of $\mathbf{3}$ were analyzed using High Resolution TEM (HRTEM) combined with SAED analysis and elemental mapping using STEM-XEDS (Figure 3). The XEDS maps of the cross section of the dendrite show a core of metallic copper (Figure $3 \mathrm{~d}$ ) covered by two successive layers containing increasing amounts of oxygen (Figure $3 \mathrm{~b}-\mathrm{c}$ ) and identified by SAED patterns as $\mathrm{Cu}_{2} \mathrm{O}$ and $\mathrm{CuO}$ (Figure $3 \mathrm{e}-\mathrm{h}$ ). The presence of these surface $\mathrm{CuO} / \mathrm{Cu}_{2} \mathrm{O}$ layers was confirmed by XPS depth analysis of the sample through $\mathrm{Ar}^{+}$etching of the surface (Figure S7). 

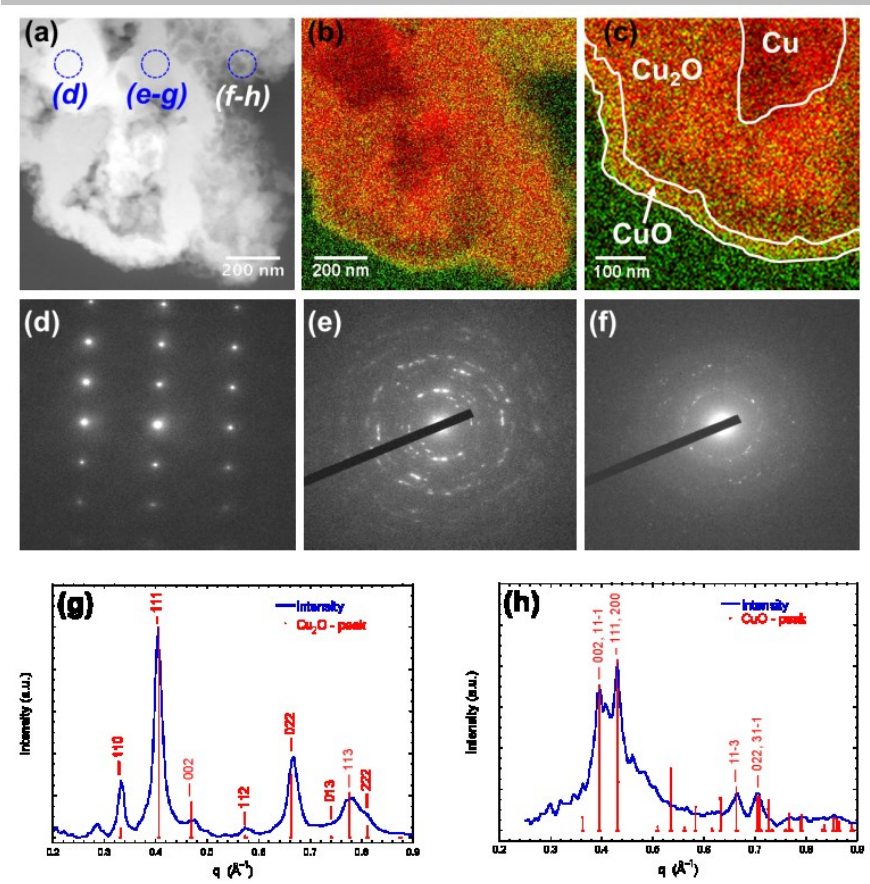

Figure 3. TEM analysis of an FIB cross section of material 3: (a) STEMHAADF (High-Angle Annular Dark-Field) image indicating areas where SAED patterns were recorded in blue circles (b)-(c) STEM-XEDS analyses (Cu in red, $O$ in green) $(d)(e)(f)$ SAED patterns of the zones indicated in (a) showing presence of metallic copper ([112] zone axis), $\mathrm{Cu}_{2} \mathrm{O}$ (Intensity profile analysis of the SAED pattern presented in (e)) or $\mathrm{CuO}$ (Intensity profile analysis of the SAED pattern presented in (f)).

These new materials were evaluated for electrocatalytic water oxidation. Representative linear sweep voltammograms (LSV) in 1.0 $\mathrm{M}$ aqueous $\mathrm{NaOH}$ solution are shown in Figure 4. Under these conditions 3 proved to be the most efficient catalytic material, with a remarkable overpotential of only $290 \mathrm{mV}$ at 10 $\mathrm{mA} . \mathrm{cm}^{-2}$, this value being to our knowledge the lowest for copper-based materials (Table S2). In order to assess the influence of the high Electrochemical Surface Area (ECSA) of studied materials (values given in Table S3) on their catalytic properties, we normalized the LSV plots by the ECSA of the electrodes (Figures S8) and compared them to a state of the art porous copper oxide OER catalyst ${ }^{[14]}$ (Figure S9). We thus observed that catalyst $\mathbf{3}$, with an ECSA-normalized overpotential of $340 \mathrm{mV} / \mathrm{cm}_{\mathrm{ECSA}}{ }^{-2}$ at $1 \mathrm{~mA}$, was more active than all the previously reported copper based catalysts even after its high surface area is taken into account (Table S2). As for many water oxidation catalysts, the Tafel plot for $\mathbf{3}$ is complex and present a strong potential dependency of the Tafel slope. ${ }^{[33,34]}$ A Tafel slope of $64 \mathrm{mV} /$ decade could be measured between 250 and $400 \mathrm{mV}$ overpotential, a comparable value with many other OER catalysts (Figure 4 , inset). ${ }^{[16,31]}$ One should however be cautious using the Tafel slope value as a benchmarking parameter since, as in the case of OER catalysts, the latter greatly depends on which elementary step of the reaction is the actual limiting one. ${ }^{[33]}$ As shown in Figure 4, the porous dendritic materials 1 and 2 are significantly less active (overpotential of $460 \mathrm{mV}$ and $370 \mathrm{mV}$ at $10 \mathrm{~mA} \cdot \mathrm{cm}^{-2}$ for 1 and 2 respectively), highlighting the strong beneficial influence of the $\mathrm{CuO}$ nanoparticle film.

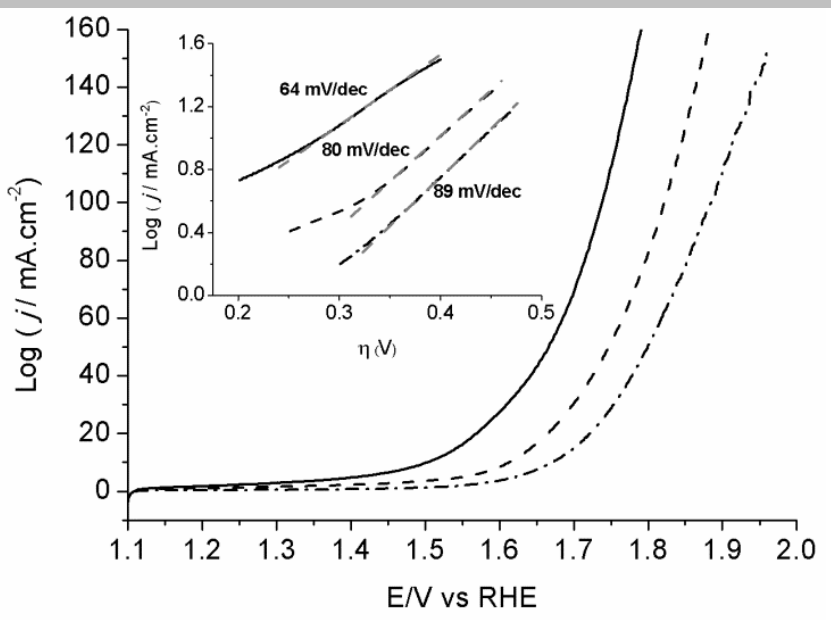

Figure 4: LSV in 1.0M NaOH of electrodes 1 (dashed-dot line), 2 (dashed line) and 3 (solid line), using a scan rate of $10 \mathrm{mV} . \mathrm{s}^{-1}$ (currents are uncorrected for resistive losses incurred within the electrolyte, all current densities are based on projected geometric area). Corresponding Tafel plots and resulting slopes are given in the inset.

In order to get insights into the relative contributions of the nanoparticle film and the dendritic copper oxide material on activity, we generated a support of identical morphology and surface area by sputter deposition of a $10 \mathrm{~nm}$ film of gold on material 2. Structural integrity of this new material, named 2-Au, was confirmed by SEM images (Figure S10) and by the fact that identical ECSA was measured for 2 and 2-Au. 2-Au was found to be less active than its parent material 2 , as witnessed by a larger overpotential of $410 \mathrm{mV}$ at $10 \mathrm{~mA} . \mathrm{cm}^{-2}$ in $1.0 \mathrm{M} \mathrm{NaOH}$ (vs. $370 \mathrm{mV}$ for 2). A CuO NP layer was then deposited on the gold film via the procedure used for 3 preparation, resulting in a new material called 2-Au-CuO (See ESI for details). LSV of these new materials in $1.0 \mathrm{M} \mathrm{NaOH}$ solution are given in Figure $\mathrm{S} 10 \mathrm{~d}$. As in the case of 3 , the $\mathrm{CuO} N \mathrm{NP}$ layer provided significantly improved activity with an overpotential of $340 \mathrm{mV}$ at $10 \mathrm{~mA} . \mathrm{cm}^{-2}$ for 2-Au-CuO in $1.0 \mathrm{M} \mathrm{NaOH}$. Yet, 2-Au-CuO is less active than $\mathbf{3}$, indicating that the copper oxide dendritic support in $\mathbf{3}$ plays a synergistic role with the CuO NP.

Interestingly, 3 was remarkably active also at lower $\mathrm{pH}$ values, (Figure S11 and table S2), presenting an overpotential of 570 $\mathrm{mV}$ at $5 \mathrm{~mA}^{-\mathrm{cm}^{-2}}$ in a $\mathrm{pH} 9.2$ potassium borate $(\mathrm{KBi})$ buffer solution, $470 \mathrm{mV}$ at $10 \mathrm{~mA} . \mathrm{cm}^{-2}$ in a pH 11 sodium carbonate solution and $365 \mathrm{mV}$ at $10 \mathrm{~mA} . \mathrm{cm}^{-2}$ in $0.1 \mathrm{M} \mathrm{NaOH}$ solution. In order to investigate the long term stability of the catalyst 3 , controlled current electrolysis was carried out at $10 \mathrm{~mA} . \mathrm{cm}^{-2}$ in a $\mathrm{pH} 11$ sodium carbonate buffer solution as well as in 0.1 or 1.0 $\mathrm{M} \mathrm{NaOH}$ solutions (Figure 5). In the case of both $\mathrm{pH} 11$ and 0.1 $\mathrm{M} \mathrm{NaOH}$ solutions the potential remained remarkably stable during the 48 hours of the reaction at values of $1.70 \mathrm{~V}$ or $1.62 \mathrm{~V}$ vs RHE, respectively, corresponding to overpotentials of only $470 \mathrm{mV}$ and $390 \mathrm{mV}$. In $1.0 \mathrm{M} \mathrm{NaOH}$, a stable potential of 1.53 $\mathrm{V}$ (corresponding to an overpotential of $300 \mathrm{mV}$ ) was observed for $10 \mathrm{~h}$, but the electrode then quickly degraded, as witnessed by the strong increase of overpotential. The loss of activity was accompanied by a degradation of the surface structuration, the dendritic framework being largely damaged. Such a fast decline in catalytic activity had been similarly reported for a CuO OER electrocatalyst. ${ }^{[13]}$ In contrast, at lower $\mathrm{pH}$ conditions $(\mathrm{pH} 11$ and $0.1 \mathrm{M} \mathrm{NaOH}$ ) both dendritic framework and surface structuration were maintained even after $48 \mathrm{~h}$ operation (SEM pictures and 
XPS analyses of the electrodes after long-term electrolysis are given in Figures S12-S14). ${ }^{[3]}$ In addition, TEM, STEM-HAADF and STEM-XEDS analyses of the catalyst after long term electrolysis in $0.1 \mathrm{M} \mathrm{NaOH}$ showed that the catalyst structure was essentially unchanged, the thin $\mathrm{CuO}$ nanoparticles layer remaining at the surface of a dense crystalline dendritic structure (Figure S15). As the only noticeable difference with the sample before electrolysis, the nanoparticle layer at the surface appeared more homogeneous in thickness.

Interestingly, the fast decline of catalytic activity of material $\mathbf{3}$ observed during long-term electrolysis at $10 \mathrm{~mA} / \mathrm{cm}^{-2}$ in $1.0 \mathrm{M}$ $\mathrm{NaOH}$ was not observed when catalytic tests were carried out at lower current densities, as previously observed with other $\mathrm{CuO}$ catalysts. ${ }^{[13]}$ For example, catalytic activity remained stable over more than $100 \mathrm{~h}$ in $1.0 \mathrm{M} \mathrm{NaOH}$ when electrolysis was carried out at $1 \mathrm{~mA} / \mathrm{cm}^{2}$ (Figure 5). This observation, together with the unexpected stability of copper oxides occasionally observed in concentrated hydroxide solutions, ${ }^{[36,37]}$ highlights the complex behavior of copper oxide materials in highly basic media, whose origin remains to be identified. In all cases, quantification of $\mathrm{O}_{2}$ formed during long term electrolyses by Gas Chromatography revealed faradic yields over $90 \%$ (see ESI for details).

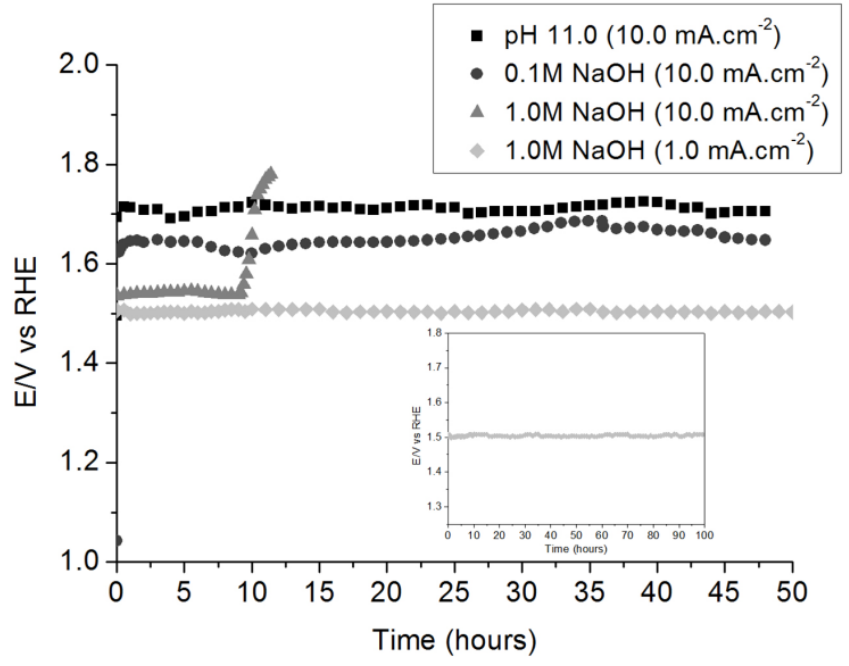

Figure 5: Plot of catalytic potential at fixed current density during long-term electrolysis for material 3 at pH $11.0\left(10 \mathrm{~mA} . \mathrm{cm}^{-2}\right)$ and in $0.1 \mathrm{M}\left(10 \mathrm{~mA} . \mathrm{cm}^{-2}\right)$ and $1 \mathrm{M} \mathrm{NaOH}$ (1 and $10 \mathrm{~mA} \cdot \mathrm{cm}^{-2}$ ) aqueous solution (See ESI for details). Inset: 100 h electrolysis in $1 \mathrm{M} \mathrm{NaOH}\left(1 \mathrm{~mA} . \mathrm{cm}^{-2}\right)$.

The results reported herein demonstrate that highly active water oxidation catalysts can be generated using nanostructured copper oxide dendritic electrodes. The dense copper oxide layer at the surface of the dendritic supports prevents the corrosion of the basal copper substrate, allowing for good and stable conductivity of the material. This new type of electrodes can be generated using simple inorganic salts and thermal treatments, allowing an easy and cost effective preparation using earth abundant copper as the sole metal, including the electrode support. These electrodes stand among the best materials for water oxidation reported in the literature, and the very versatile methods used for their generation could likely be extended to other metals.

\section{Acknowledgements}

This work was supported by the Fondation de l'Orangerie for individual Philanthropy and its donors. The authors acknowledge LabEx MICHEM (ANR-11-IDEX-0004-02) for the use of nano/micro-Raman facilities in UPMC. Preparation of FIB cross sections benefited from support from the French RENATECH network.

Keywords: copper oxide $\bullet$ water oxidation $\bullet$ porous electrode $\bullet$ electrocatalysis $\cdot$ electrodeposition

[1] V. Artero, M. Chavarot-Kerlidou, M. Fontecave, Angew. Chem. Int. Ed. 2011, 50, 7238-7266.

[2] D. G. Nocera, Acc. Chem. Res. 2012, 45, 767-776.

[3] X. Li, X. Hao, A. Abudula, G. Guan, J. Mater. Chem. A 2016, 4, 1197312000.

[4] M. W. Kanan, D. G. Nocera, Science 2008, 321, 1072-1075.

[5] H. Dau, C. Limberg, T. Reier, M. Risch, S. Roggan, P. Strasser, ChemCatChem 2010, 2, 724-761.

[6] B. Zhang, X. L. Zheng, O. Voznyy, R. Comin, M. Bajdich, M. GarciaMelchor, L. L. Han, J. X. Xu, M. Liu, L. R. Zheng, F. P. G. de Arquer, C. T. Dinh, F. J. Fan, M. J. Yuan, E. Yassitepe, N. Chen, T. Regier, P. F. Liu, Y. H. Li, P. De Luna, A. Janmohamed, H. L. L. Xin, H. G. Yang, A. Vojvodic, E. H. Sargent, Science 2016, 352, 333-337.

[7] L. A. Stern, L. G. Feng, F. Song, X. L. Hu, Energy Environ. Sci. 2015, 8, 2347-2351.

[8] J. Luo, J.-H. Im, M. T. Mayer, M. Schreier, M. K. Nazeeruddin, N.-G Park, S. D. Tilley, H. J. Fan, M. Grätzel, Science 2014, 345, 1593-1596.

[9] X. Xu, F. Song, X. Hu, Nat. Commun. 2016, 7, 12324

[10] J. W. D. Ng, M. García-Melchor, M. Bajdich, P. Chakthranont, C. Kirk, A Vojvodic, T. F. Jaramillo, Nat. Energy 2016, 1, 16053.

[11] X. Liu, S. Cui, Z. Sun, P. Du, Electrochim. Acta 2015, 160, 202-208.

[12] X. Liu, H. Jia, Z. Sun, H. Chen, P. Xu, P. Du, Electrochem. Commun. 2014, 46, 1-4

[13] X. Liu, S. Cui, Z. Sun, Y. Ren, X. Zhang, P. Du, J. Phys. Chem. C 2016, $120,831-840$

[14] K. S. Joya, H. J. M. de Groot, ACS Catal. 2016, 6, 1768-1771.

[15] J. Du, Z. Chen, S. Ye, B. J. Wiley, T. J. Meyer, Angew. Chem. Int. Ed. 2015, 54, 2073-2078.

[16] N. Cheng, Y. Xue, Q. Liu, J. Tian, L. Zhang, A. M. Asiri, X. Sun Electrochim. Acta 2015, 163, 102-106.

[17] C.-C. Hou, W.-F. Fu, Y. Chen, Chemsuschem 2016, 9, 2069-2073.

[18] This system is protected by the patent application FR1653753, "Electrode metal / chalcogénure métallique", 27/04/2016.

[19] H.-C. Shin, M. Liu, Chem. Mat. 2004, 16, 5460-5464

[20] H. C. Shin, J. Dong, M. Liu, Adv. Mat. 2003, 15, 1610-1614.

[21] T. N. Huan, P. Simon, G. Rousse, I. Génois, V. Artero, M. Fontecave, Chem. Sci. 2017, 8, 742-747.

[22] B. Beverskog, I. Puigdomenech, J. Electrochem. Soc. 1997, 144, 3476 3483.

[23] XPS studies of 1 confirmed that the electrode consists in bulk $\mathrm{Cu}$ covered by a thin layer of Cu2O (Figure S1)

[24] S. K. Chawla, N. Sankarraman, J. H. Payer, Journal of Electron Spectroscopy and Related Phenomena 1992, 61, 1-18.

[25] S. T. Mayer, R. H. Muller, J. Electrochem. Soc. 1992, 139, 426-434

[26] T. N. Huan, E. S. Andreiadis, J. Heidkamp, P. Simon, E. Derat, S. Cobo, G. Royal, A. Bergmann, P. Strasser, H. Dau, V. Artero, M. Fontecave, J. Mater. Chem. A 2015, 3, 3901-3907.

[27] T. N. Huan, P. Simon, A. Benayad, L. Guetaz, V. Artero, M. Fontecave, Chem.-Eur. J. 2016, 22, 14029-14035.

[28] M. B. Gawande, A. Goswami, F.-X. Felpin, T. Asefa, X. Huang, R. Silva, X. Zou, R. Zboril, R. S. Varma, Chem. Rev. 2016, 116, 3722-3811.

[29] M. J. Kim, P. F. Flowers, I. E. Stewart, S. Ye, S. Baek, J. J. Kim, B. J. Wiley, J. Am. Chem. Soc. 2016.

[30] When electrodeposition of $\mathrm{CuO}$ nanoparticles from $\mathrm{Cu}$ (imidazole) ${ }_{4} \mathrm{Cl}_{2}$ was achieved using 3, 5 or 10 voltammetric cycles, a much thicker layer of deposited material was observed but the resulting material was much less active, while when only 1 cycle was used, the material presented a thiner layer of nanoparticles and a reduced activity vs. 3 (see ESI for details) 
[31] Y. Deng, A. D. Handoko, Y. Du, S. Xi, B. S. Yeo, ACS Catal. 2016, 6 2473-2481.

[32] It should be noted however that the presence of $\mathrm{Cu}$ (Imidazole $)_{4} \mathrm{Cl}_{2}$ is necessary to the deposition of the $\mathrm{CuO}$ nanoparticles. We could not obtain similar structures and activities when no copper complex was present, in the presence of imidazole ligand only or using other $\mathrm{N}$ containing copper complexes such as $\mathrm{Cu}$ (cyclam) $\mathrm{Cl}_{2}$ or $\mathrm{Cu}\left(\mathrm{Me}_{4}\right.$ cyclam) $\mathrm{Cl}_{2}$, all other conditions being the same.

[33] T. Shinagawa, A. T. Garcia-Esparza, K. Takanabe, Sci. Rep. 2015, 5, 13801.

[34] F. Dionigi, P. Strasser, Adv. Energy Mater. 2016, 1600621.

[35] Powder XRD analysis of 3 after $10 \mathrm{~h}$ electrolysis at $\mathrm{pH} 11$ and 10 $\mathrm{mA} / \mathrm{cm}^{2}$ (Figure S16) revealed strong signals associated to $\mathrm{Cu}$ and $\mathrm{Cu}_{2} \mathrm{O}$, indicating that the material is efficiently passivated by the $\mathrm{CuO}$ layer in these conditions.

[36] Y. Li, S. Chang, X. Liu, J. Huang, J. Yin, G. Wang, D. Cao, Electrochim. Acta 2012, 85, 393-398.

[37] M. Kuang, P. Han, Q. Wang, J. Li, G. Zheng, Adv. Funct. Mater. 2016 $26,8555-8561$. 